\title{
Cognitive and Emotional Representations of Terror Attacks: A Cross-Cultural Exploration
}

\author{
Shoshana Shiloh, ${ }^{1 *}$ Gülbanu Güvenç, $^{2}$ and Dilek Önkal ${ }^{2}$
}

\begin{abstract}
A questionnaire measuring cognitive and affective representations of terror risk was developed and tested in Turkey and Israel. Participants in the study were university students from the two countries $(n=351)$. Four equivalent factors explained terror risk cognitions in each sample: costs, vulnerability, trust, and control. A single negative emotionality factor explained the affective component of terror risk representations in both samples. All factors except control could be measured reliably. Results supported the validity of the questionnaire by showing expected associations between cognitions and emotions, as well as indicating gender differences and cultural variations. Current findings are discussed in relation to previous results, theoretical approaches, and practical implications.
\end{abstract}

KEY WORDS: Cross-cultural comparisons; gender; risk perception; terror

\section{INTRODUCTION}

Terror has become a major ongoing concern in many parts of the world in recent years (Deisler, 2002). As a result of "probability neglect" (failure to attend to rules of probability) people are often more concerned about risks of terror than about statistically larger risks that they confront in everyday life (Sunstein, 2003). Beyond direct losses due to terror, the ripple effects of public fear of terror produces even more costs. For example, avoiding the risk of terror led to a higher death toll by car accidents after the attacks of 9/11 due to many Americans driving instead of flying (Gigerenzer, 2004).

There is ample evidence of significant short-term impacts on victims and nonvictims in different societies that suffered from terror. In the United States, within the first few months after 9/11, close association with a victim was related to sleep problems,

\footnotetext{
${ }^{1}$ Tel Aviv University, Psychology, Tel Aviv, Israel.

${ }^{2}$ Bilkent University, Business Administration, Ankara, Turkey.

*Address correspondence to Shoshana Shiloh, Tel Aviv University, Psychology, Tel Aviv, Israel; shoshi@freud.tau.ac.il.
}

increased drinking and smoking, and help-seeking (Adams, Ford, \& Dailey, 2004). Within 4 months of the attack on the Pentagon, mental health concerns were common among Pentagon employees (Jordan et al., 2004). A survey among New York residents 1 year after the attack showed that the greater the exposure to the World Trade Center attack, the poorer the person's psychological well-being, even after controlling for demographic characteristics, other stressors, and social psychological resources (Adams, Boscarino, \& Galea, 2006). In France, 2.6 years after the 1995-1996 bombings, there was a high prevalence of posttraumatic stress disorder (PTSD) among those exposed to the attacks (Verger et al., 2004). Similarly, victims and families of terror attacks in Spain had a greater prevalence of depressive and anxiety disorders than controls, which were directly related to the degree of involvement in the terror attack (Baca Baldomero et al., 2004). Among a representative sample of Israelis after 2 years of ongoing terror attacks, $16.4 \%$ had been directly exposed to a terror attack, but $76.7 \%$ had at least one traumatic stress-related symptom, $9.4 \%$ met criteria for acute stress disorder, $58.6 \%$ reported feeling depressed, and $60.45 \%$ expressed a low sense of 
safety with respect to themselves (Bleich, Gelkopf, \& Solomon, 2003).

The current research focuses on the psychological mechanisms underlying the impact of terror on individuals, even those who have not been victimized directly. In one study among NY residents after the 9/11 attacks, the motivation to care for others was suggested as a mediator between the terror experience and anxiety (Woike \& Matic, 2004, Study 1). Our interest was in studying another important mediating mechanism -individuals' representations and appraisals of terror attacks. Since the introduction of the transactional theory of stress (Lazarus \& Folkman, 1984), it is widely accepted that lay representations about and appraisals of threatening situations are more strongly related to distress than the objective threats themselves. This assertion has been validated with regard to many threats, including lifethreatening diseases (Fife, 2005), work stress (Kinman \& Jones, 2005), technological disasters (Lange, Fleming, \& Toussaint, 2004), and exposure to terror (Lavi $\&$ Solomon, 2005). Given the established importance of representations on outcomes, understanding people's perceptions of terror-related risk is essential for predicting adverse effects, and for developing interventions aimed at easing these adversities.

Current knowledge about people's representations of terror-related risks is still quite limited. General danger appraisals, estimated probability of occurrence, and worries constitute the partial aspects that have been investigated. In a study among Palestinian youth, objective exposure to violence was related to higher stress symptoms only at higher levels of subjective appraisal of danger (Lavi \& Solomon, 2005). Fischhoff et al. (2005) examined the effects of experience, memory, and emotion on judgments of terror-related risks (probability of occurrence) in an American sample, and found that respondents' future risk judgments changed in ways consistent with their reported personal experiences. A fear-inducing manipulation increased risk estimates, whereas an anger-inducing manipulation reduced them in both predictions and memories. Thus, priming emotions shaped not only perceptions of an abstract future but also perceptions of the concrete past. These findings correspond with evidence that emotional representations play a major role in regulating reactions to terror attacks. For example, only emotion-focused coping efforts predicted stress reactions to terror attacks among Israeli adolescents (Zeidner, 2005); and willingness to fly or to travel to a destination was predicted by worry even after controlling for cognitive estimations of the likelihood that terrorist attacks would occur (Bergstrom \& McCaul, 2004; Fischhoff et al., 2004).

Behavioral risk research has demonstrated that the representation of risk is complex and includes a richer set of elements than probability estimates and emotions. According to Fischhoff et al. (1978), the public perceives risk as a multidimensional concept where subjective probability is just one of the factors. They proposed a model that delineates a number of explanatory dimensions, such as knowledge, controllability, voluntariness, and dread. Dread was found as the major determinant of public perception and acceptance of a wide range of hazards. Slovic (1987) characterized dread as consisting of perceived lack of control, catastrophic potential, fatal consequences, and the inequitable distribution of risks and benefits.

In addition to cognitive processes, the social amplification of risk framework (Kasperson et al., 1988) maintains that representations of risk are created through social processes like communication from "stations of amplification or attenuation" (e.g., media) that attach social values to the information, or interactions with one's cultural peer groups to interpret and validate the information. Thus, the sociocultural context has been considered essential for understanding the shared meaning of risk within societies (Heine \& Lehman, 1995). Cultural differences were indeed found in perceptions of childhood pedestrian road safety (Lam, 2005), perceived risk of genetically modified food items (Finucane \& Holup, 2005), and financial risks (Weber \& Hsee, 1998). Mental health reactions after terror attacks in Nairobi, Kenya and Oklahoma City showed many similarities in the two cultures in postdisaster psychopathology, but coping responses were quite different (North et al., 2005).

The present research was designed to disclose the cognitive and emotional contents of risk representations of terror attacks. Because of its exploratory nature, a qualitative study preceded a quantitative investigation. The research started with open-ended interviews, portraying respondents' thoughts and feelings about terror attacks. On the basis of the elicited themes, a questionnaire was constructed that enabled a closer examination of the structure of representations. To place terror risk representations in a cultural context, we administered the questionnaire in two countries, Turkey and Israel. These Islamic and Jewish countries share an ongoing threat of terror attacks, but differ in their sociocultural backgrounds. To the best of our knowledge, Turkish and Israeli cultures have not been compared yet with regard to risk 
perceptions or relevant variables, but other indications of differences between these cultures exist. In particular, Israel and Turkey were found close on several value dimensions (e.g., egalitarianism) and distant on others (e.g., affective autonomy, conservatism, mastery) in a study among school teachers (Schwartz, 1999). In another study, Israel and Turkey were found dissimilar in items relating to economic satisfaction, belief in a just world, and opposition to social welfare, a dimension linked to modernization, civil social capital, and government social capital (Allen, $\mathrm{Ng}, \&$ Leiser, 2005).

Conducting the study in two countries with such different cultures gave us the opportunity to examine cross-cultural similarities and differences in representations of terror-related risks. A cross-cultural approach for studying risk was suggested as essential for addressing global risks both at the individual and societal levels (McDaniels \& Gregory, 1991). Previous research showed a common dimensional structure of risk perceptions across cultures, but cultures differed with regard to overall risk perceptions and the salience of associated factors (Slovic, 1992). Using a standard measure of terror risk perception in the present study was, therefore, expected to disclose common structural determinants of terror risk perception while pointing to cultural differences in the perceived salience of specific factors. The preliminary nature of this research has not allowed for more specific hypotheses regarding the common structure and the nature of cultural differences.

\section{METHOD}

\subsection{Participants}

A total of 185 social sciences students at Bilkent University (Ankara) and 166 psychology students at Tel Aviv University volunteered to participate in the study. The survey was conducted at Bilkent University in February 2005 and at Tel Aviv University in May 2005. The Turkish sample consisted of 88 male and 97 female respondents, aged $18-34$ years $(M=22.66$, $S D=2.56)$; the Israeli sample consisted of 41 males and 125 females, aged $18-45$ years $(M=24.81, S D=$ 3.74).

\subsection{Measures}

\subsubsection{Demographic and Background Data}

Variables that were thought to have potential impact on terror risk perceptions were measured. Age, gender, and university major were recorded. In addition, personal or relatives' direct involvement in a terror attack was reported, and respondents were asked about their perceived knowledge about terror attacks in their own country and abroad $(1=$ very little to $4=$ very much). Significant differences were found between the two participant groups with respect to age $(t=6.21, p<0.01)$, gender $(p<0.01)$, and perceived knowledge of terror attacks $(t=3.54$, $p<0.01)$. Israeli respondents were significantly older, reporting less knowledge of terror attacks than their Turkish counterparts, and the female composition was higher. However, there were no significant differences between the two groups regarding their personal experience with terrorist attacks $\left(\chi^{2}=0.90, p=0.34\right)$. These differences were considered in data analyses, and did not appear to exert biasing influences on the substantive findings of the study.

\subsubsection{Terror Risk Perception Questionnaire (TRPQ)}

A risk perception questionnaire was developed to measure cognitive and emotional representations of terror attacks. The self-regulatory theory (Leventhal, 1970) maintains that threat generates two parallel representations: one cognitive and one emotional. Accordingly, a two-part questionnaire was constructed. The first part measured individuals' cognitive perceptions of terror attacks on a seven-point scale (where $1=$ strongly disagree, $7=$ strongly agree). The questionnaire included 27 items like: "If I was exposed to a terrorist attack, my life would be psychologically harmed" and "My chance of being exposed to a terrorist attack is less than that of other people." The second part of the questionnaire aimed to assess emotional representations and was constructed as a semantic differential scale that included 10 negative affects. The emotions were fear, helplessness, hopelessness, anger, intolerance, pain, loneliness, insecurity, sadness, and anxiety. The participants reported their feelings about terrorist attacks on a seven-point scale (where $1=$ "I do not feel" and $7=$ "I strongly feel"). A psychometric analysis of the questionnaire is presented in Section 3.

The items were generated from two waves of interviews with students at Bilkent University. Turkish people have been exposed in recent years to terrorist attacks from separatist terror groups as well as Islamic terror groups; thus, their perceived terror risk might represent a wide perspective and be a productive source for constructing a terror risk perception questionnaire. The first wave of interviews was conducted 2 months after the suicide car bomb attacks 
in Istanbul in 2003. We focused on this vivid incident and tried to elicit thoughts and emotions on this recent terrorist event. Given the potential limitations of this type of focusing, in the second set of interviews we asked for respondents' thoughts and emotions on terrorist events in general. Overall, 50 individuals participated in the qualitative interview study, 29 male and 21 female, aged $19-32$ years $(M=23.5$, $S D=3.07)$. Their gender and age distributions were statistically comparable to those of the Turkish participants in the main study.

Thirty graduate business students volunteered to take part in the first set of interviews. Participants were asked how they felt and what they thought just after the attacks in Istanbul, whether their feelings and thoughts had changed over time, and what kind of changes they had experienced. Themes expressed by the respondents more than once were recorded. Eighteen cognitive and nine emotion items were generated this way. The second wave of interviews was conducted on another group of 20 undergraduate volunteering students about 1 year later. This time, participants were asked about their thoughts and feeling about their risk of being exposed to terror attacks in general. Respondents reported thinking about terror attacks occurring all over the world (9/11 and separatist terror group attacks in Turkey were the most common examples provided by the respondents). Twenty-one themes were generated as a result of these interviews, 12 repeated those elicited in the first set of interviews and nine were new. All the themes recorded in both studies were represented as items in the initial version of the questionnaire. Frequency of expression for each of the cognitive items is presented in Table I. Frequencies of expression of the emotional items were: fear, $34 \%$; helplessness, $26 \%$; hopelessness, $14 \%$; anger, $58 \%$; intolerance, $4 \%$; pain, $34 \%$; loneliness, $4 \%$; insecurity, $52 \%$; sadness, $64 \%$; and anxiety, $54 \%$.

\subsection{Procedure}

Participants were recruited at Bilkent University and Tel Aviv University in response to announcements at the end of regular classes. The questionnaire was initially constructed in Turkish and translated into English and Hebrew. Translations were checked by backward procedures using people fluent in the relevant languages. Participants filled out the questionnaire in their native language, which took about 15 minutes, and was conducted in groups after regular class time.

\section{RESULTS}

\subsection{Internal Structure of the Terror Risk Perception Questionnaire (TRPQ)}

Exploratory principal components factor analysis with varimax rotation was conducted on the 27-item cognitive scale. Based on Cattell's scree test, a four-factor solution appeared to be the best choice for the factorial structure. Four items that did not load on a specific factor in either sample, and three items that loaded on different factors in the Turkish and Israeli samples, were eliminated to obtain a clear structure and ensure internal consistency and crosscountry standardization. In addition, two items that had factor loadings below 0.32 in all of the factors were eliminated since they are not statistically meaningful in representing a particular factor (Tabachnik \& Fidell, 1996). For example, the excluded item "If I was exposed to a terrorist attack, the possibility of needing care from others frightens me" was closer to the (lack of) control factor among Turkish respondents and to the costs factor among Israeli respondents. Eliminated items were examined to see whether they represented any particular dimension, but no reliable factors were obtained. They were, however, retained as single items for cross-country comparisons.

The factor loadings and item-total correlations of the final 18-item version of the TRPQ in the Turkish and Israeli samples are shown in Table I. To further support the congruence of factor solutions obtained in both samples, factor congruence coefficients were calculated (CC; Cattell, 1978). $R_{\mathrm{c}}$ values were $0.95,0.94$, 0.90 , and 0.74 for factors $1,2,3$, and 4 , respectively. Coefficient of congruence values of 0.90 or above represent very high, and $0.70-0.79$ represent moderate, agreement of factor solutions (Sakamoto et al., 1998). Catell's salient similarity indexes were $0.96,0.86,0.63$, and 0.57 for factors $1,2,3$, and 4 , respectively. With 30 variables and a corresponding hyperplane (hp) count, the $p$ values obtained were $p<0.001$.

Item-total correlations for each of the four factors ranged from 0.21 to 0.83 in both samples (Table I), indicating adequate item effectivity (Aiken, 1994). The first factor, labeled "costs," included items related to the severe consequences of a terror attack. The second factor, "vulnerability," contained items about the chances that one would be exposed to a terror attack. The third factor, "trust," consisted of items representing trust in authorities like government and public organizations for security and help. The last factor, labeled "control," included items that were associated with perceived personal helplessness and lack of control over terror risk. 
Table I. Factor Loadings, Item-Total Correlations (in Parentheses) and \% Being Expressed in Interviews, of Cognitive TRPQ Items in Israeli and Turkish Samples

\begin{tabular}{|c|c|c|c|c|c|c|c|c|c|}
\hline \multirow[b]{3}{*}{ Item } & \multicolumn{8}{|c|}{ Factor Loadings and Item-Total Correlations } & \multirow{3}{*}{$\begin{array}{l}\% \text { Being } \\
\text { Expressed }\end{array}$} \\
\hline & \multicolumn{2}{|c|}{$\mathrm{I}$} & \multicolumn{2}{|c|}{ II } & \multicolumn{2}{|c|}{ III } & \multicolumn{2}{|c|}{ IV } & \\
\hline & Israel & Turkey & Israel & Turkey & Israel & Turkey & Israel & Turkey & \\
\hline $\begin{array}{l}\text { If I was exposed to a terrorist } \\
\text { attack, my life would be more } \\
\text { difficult }\end{array}$ & $0.65(0.53)$ & $0.72(0.57)$ & & & & & & & 70 \\
\hline $\begin{array}{l}\text { Thinking I can be exposed to a } \\
\text { terrorist attack negatively } \\
\text { affects my daily life }\end{array}$ & $0.38(0.25)$ & $0.47(0.35)$ & & & & & & & 6 \\
\hline $\begin{array}{l}\text { Terrorist attacks are fearful } \\
\text { events }\end{array}$ & $0.48(0.38)$ & $0.54(0.42)$ & & & & & & & 4 \\
\hline $\begin{array}{l}\text { If I was exposed to a terrorist } \\
\text { attack, I would think that it is } \\
\text { unfair }\end{array}$ & $0.47(0.38)$ & $0.56(0.42)$ & & & & & & & 28 \\
\hline $\begin{array}{l}\text { If I was exposed to a terrorist } \\
\text { attack, my life would be } \\
\text { psychologically harmed }\end{array}$ & $0.86(0.72)$ & $0.83(0.70)$ & & & & & & & 72 \\
\hline $\begin{array}{l}\text { If I was exposed to a terrorist } \\
\text { attack, I would need help from } \\
\text { my relatives or close friends to } \\
\text { cope with the trauma }\end{array}$ & $0.75(0.61)$ & $0.54(0.41)$ & & & & & & & 24 \\
\hline $\begin{array}{l}\text { If I was exposed to a terrorist } \\
\text { attack, I would often catch } \\
\text { myself thinking about it }\end{array}$ & $0.82(0.66)$ & $0.63(0.48)$ & & & & & & & 18 \\
\hline $\begin{array}{l}\text { If I was exposed to a terrorist } \\
\text { attack, my relationship } \\
\text { (flirtation, marriage, etc.) } \\
\text { would be endangered }\end{array}$ & $0.60(0.47)$ & $0.62(0.46)$ & & & & & & & 8 \\
\hline $\begin{array}{l}\text { My chance of being exposed to a } \\
\text { terrorist attack is less than that } \\
\text { of other people }\end{array}$ & & & $0.75(0.53)$ & $0.72(0.52)$ & & & & & 12 \\
\hline $\begin{array}{l}\text { I believe that I won't be exposed } \\
\text { to a terrorist attack }\end{array}$ & & & $0.41(0.22)$ & $0.65(0.41)$ & & & & & 20 \\
\hline $\begin{array}{l}\text { My chance of being exposed to a } \\
\text { terrorist attack is less than that } \\
\text { of others of my age }\end{array}$ & & & $0.76(0.53)$ & $0.78(0.57)$ & & & & & 4 \\
\hline $\begin{array}{l}\text { My chance of being exposed to a } \\
\text { terrorist attack is less than that } \\
\text { of others of my sex }\end{array}$ & & & $0.87(0.69)$ & $0.73(0.50)$ & & & & & 8 \\
\hline $\begin{array}{l}\text { Security forces (police, army, } \\
\text { etc.) will do their best after the } \\
\text { terrorist attacks }\end{array}$ & & & & & $0.68(0.45)$ & $0.87(0.74)$ & & & 18 \\
\hline $\begin{array}{l}\text { I trust the government to } \\
\text { prevent future terrorist attacks }\end{array}$ & & & & & $0.85(0.62)$ & $0.92(0.83)$ & & & 4 \\
\hline $\begin{array}{l}\text { I trust the police to prevent } \\
\text { future terrorist attacks }\end{array}$ & & & & & $0.87(0.71)$ & $0.91(0.81)$ & & & 4 \\
\hline $\begin{array}{l}\text { Being exposed to a terrorist } \\
\text { attack is a result of factors } \\
\text { beyond my control }\end{array}$ & & & & & & & $0.80(0.44)$ & $0.66(0.39)$ & 70 \\
\hline $\begin{array}{l}\text { Every individual can be exposed } \\
\text { to terrorist attacks }\end{array}$ & & & & & & & $0.52(0.21)$ & $0.66(0.34)$ & 34 \\
\hline $\begin{array}{l}\text { I can do nothing to avoid being } \\
\text { exposed to a terrorist attack }\end{array}$ & & & & & & & $0.71(0.29)$ & $0.73(0.28)$ & 50 \\
\hline
\end{tabular}

Factor I - "costs"; Factor II - "vulnerability"; Factor III - "trust”; Factor IV - “control.”

Frequency of expression of each of the cognitive items in exploratory interviews is presented in the right column. 
Variances explained by the "costs," "vulnerability," "trust," and "control" factors were $17.99 \%$, $12.74 \%, 14.07 \%$, and $9.08 \%$ in the Turkish sample, while being $19.39 \%, 13.14 \%, 11.79 \%$, and $8.91 \%$ in the Israeli sample. Thus, the four-factor solution accounted for $53.88 \%$ of the total variance in the Turkish sample and $53.24 \%$ of the variance in the Israeli sample. The factor contributing the most to the explained variance in both samples was "costs," and the factor contributing the least to the explained variance was "control." "Trust" was the second contributor to explained variance in the Turkish sample and third in the Israeli sample. Internal consistencies for the costs, vulnerability, trust, and control subscales in the Turkish sample were $0.77,0.71,0.89$ and 0.51 , respectively; in the Israeli sample, they were $0.78,0.69,0.76$, and 0.48 , respectively. Given the generally accepted benchmarks around 0.70 (McIntire \& Miller, 2000), measurements of all dimensions except control may be considered reliable.

A separate exploratory principal components factor analysis was conducted on the affective part of the questionnaire. This yielded one factor accounting for $47.93 \%$ of the total variance in the Turkish sample and $42.58 \%$ in the Israeli sample. Factor loadings of specific emotion scales ranged from 0.36 to 0.81 in the Turkish sample, and from 0.43 to 0.80 in the Israeli sample. Internal consistencies of the affective scale in the Turkish and Israeli samples were 0.87 and 0.84 , respectively. Item-total correlations ranged from 0.36 to 0.73 in both samples. Intolerance and loneliness were retained despite their low frequency of expression $(4 \%)$ because of their contribution to the scale's reliability. These results suggest that a single affective scale can be adequately used to measure feelings about terror attacks. The final form of the Terror Risk Perception Questionnaire (TRPQ) for measuring cognitive and emotional aspects of terror risk representations may be available upon request.

\subsection{Correlations Between Cognitions and Emotions about Terror}

Pearson correlations between cognitive factors and affect scores are presented in Table II. Findings in both samples indicated that the more costs and the less control participants perceived regarding terror attacks, the more negative emotions they expressed. In the Turkish sample, higher perceived vulnerability to terror attacks was also related to stronger negative emotions. The costs factor had the highest correlation
Table II. Pearson Correlations Between Cognitive Factors and Negative Affect

\begin{tabular}{lccccc}
\hline & \multicolumn{2}{c}{ Turkey $(n=185)$} & & \multicolumn{2}{c}{ Israel $(n=166)$} \\
\cline { 2 - 3 } \cline { 5 - 6 } Factors & $r$ & $p$-Value & & $r$ & $p$-Value \\
\hline Costs & 0.59 & 0.00 & & 0.51 & 0.00 \\
Vulnerability & 0.24 & 0.01 & & -0.03 & 0.66 \\
Trust & -0.02 & 0.81 & & 0.05 & 0.49 \\
Control & -0.23 & 0.01 & & -0.17 & 0.03 \\
\hline
\end{tabular}

with negative affect in both samples. No significant correlations were found between trust and negative affect in either sample.

\subsection{Relationships Between TRPQ, Demographic Variables, Experience with Attacks, and Perceived Knowledge of Terror Attacks}

Age was unrelated to TRPQ scores in both samples. Gender, however, was significantly related to costs, vulnerability, and negative affect scores in both samples (Table III). Female respondents had stronger perceptions of costs, vulnerability, and negative affect than male respondents.

While no significant associations were found in the Turkish sample between personal experience with terror attacks and TRPQ scores, Israeli respondents with terror experiences had higher emotional scores in the TRPQ $(m=4.82, S D=0.91)$ compared to those without personal experience $(m=4.19, S D=1.05$, $F=12.54, p<0.01)$. Israelis who presented themselves as having greater knowledge of terror attacks (in Israel) had higher vulnerability perceptions than Israelis with less perceived knowledge $(r=0.19, p<$ $0.05)$. However, Turkish participants with greater perceived knowledge of terror attacks (in Turkey) trusted authorities more than those with an average level of perceived knowledge $(r=0.18, p<0.02)$.

\subsection{Comparison Between Turkish and Israeli Groups on TRPQ Scores}

Differences in cognitive and affective representations of terror between Turkish and Israeli respondents were assessed by MANOVA. The mean ratings and corresponding standard deviations of the TRPQ scores for the two samples are summarized in Table IV. Cross-country comparisons of the items eliminated from the questionnaire are presented in Table V. 
Table III. Gender Differences in Mean Ratings of TRPQ Scores in the Turkish and Israeli samples

\begin{tabular}{|c|c|c|c|c|c|c|}
\hline \multirow[b]{2}{*}{ Factors } & \multicolumn{3}{|c|}{ Turkey } & \multicolumn{3}{|c|}{ Israel } \\
\hline & Male $(n=88)$ & Female $(n=97)$ & $F$-Statistic & Male $(n=41)$ & Female $(n=125)$ & $F$-Statistic \\
\hline Costs & 4.75 & 5.39 & $22.17^{* *}$ & 4.38 & 5.07 & $20.39^{* *}$ \\
\hline Vulnerability ${ }^{\mathrm{a}}$ & 2.80 & 2.44 & $4.35^{*}$ & 2.95 & 2.46 & $8.56^{* *}$ \\
\hline Trust & 4.29 & 3.90 & 2.75 & 3.91 & 4.05 & 0.39 \\
\hline Control $^{\mathrm{a}}$ & 5.67 & 5.83 & 1.22 & 4.88 & 5.26 & $5.12^{*}$ \\
\hline Negative affect & 4.86 & 5.50 & $15.44^{* *}$ & 3.94 & 4.49 & $8.87^{* *}$ \\
\hline
\end{tabular}

${ }^{\text {a Reverse scoring. }}$

${ }^{*} p<0.05$.

${ }^{* *} p<0.01$.

\begin{tabular}{lcccc}
\hline Factors & Turkey $(n=185)$ & Israel $(n=166)$ & $F$-Statistic & $p$-Value \\
\hline Costs & $5.09(0.97)$ & $4.90(0.89)$ & 3.47 & 0.06 \\
Vulnerability $^{\mathrm{a}}$ & $2.61(1.18)$ & $2.58(0.96)$ & 0.07 & 0.79 \\
Trust $_{\text {Control }}^{\mathrm{a}}$ & $4.08(1.62)$ & $4.02(1.23)$ & 0.18 & 0.67 \\
Fear $_{\text {Helplessness }}^{5.75(1.03)}$ & $5.16(0.95)$ & 30.92 & 0.00 \\
Hopelessness & $5.43(1.61)$ & $4.72(1.62)$ & 16.57 & 0.00 \\
Anger & $5.17(1.89)$ & $5.03(1.57)$ & 0.55 & 0.46 \\
Intolerance & $4.53(1.91)$ & $3.61(1.51)$ & 24.28 & 0.00 \\
Pain & $6.32(1.27)$ & $4.88(1.62)$ & 87.05 & 0.00 \\
Loneliness & $5.04(1.88)$ & $3.92(1.74)$ & 33.22 & 0.00 \\
Insecurity & $5.50(1.52)$ & $5.01(1.70)$ & 7.79 & 0.01 \\
Sadness & $3.63(1.98)$ & $2.45(1.42)$ & 40.72 & 0.00 \\
Anxiety & $4.91(1.95)$ & $4.36(1.68)$ & 7.95 & 0.01 \\
Mean negative affect & $5.98(1.26)$ & $5.16(1.53)$ & 30.30 & 0.00 \\
& $5.47(1.63)$ & $4.43(1.80)$ & 32.45 & 0.00 \\
\end{tabular}

Table IV. Means and Standard Deviations of TRPQ Scores in the Turkish and Israeli Samples

${ }^{\mathrm{a}}$ Reverse scoring.

Table V. Means and Standard Deviations of the Eliminated Items in the Turkish and Israeli Samples

\begin{tabular}{|c|c|c|c|c|}
\hline Items & $\begin{array}{l}\text { Turkey } \\
(n=185)\end{array}$ & $\begin{array}{c}\text { Israel } \\
(n=166)\end{array}$ & $F$-Statistic & $p$-Value \\
\hline $\begin{array}{l}\text { 1. Thinking that those who are close to me can be exposed to terrorist attacks makes } \\
\text { me feel afraid }\end{array}$ & $6.12(1.42)$ & $5.43(1.50)$ & 26.53 & 0.00 \\
\hline $\begin{array}{l}\text { 4. Not being in crowded places can prevent me from being exposed to a terrorist } \\
\text { attack }\end{array}$ & $3.47(1.86)$ & $3.92(1.68)$ & 3.32 & 0.07 \\
\hline 5. Thinking that I can be exposed to a terrorist attack makes me feel anxious & $4.89(1.88)$ & $4.08(1.83)$ & 17.24 & 0.00 \\
\hline $\begin{array}{l}\text { 9. Working in companies that can be targets of the terrorist groups will increase my } \\
\text { chance of being exposed to a terrorist attack }\end{array}$ & $5.28(1.55)$ & $4.86(1.41)$ & 6.89 & 0.01 \\
\hline $\begin{array}{l}\text { 14. If I lived in Istanbul/Jerusalem, my chance of being exposed to a terrorist attack } \\
\text { would be higher }\end{array}$ & $4.39(1.73)$ & $4.20(1.61)$ & 0.62 & 0.43 \\
\hline $\begin{array}{l}\text { 17. If I was exposed to a terrorist attack, the possibility that I might need other } \\
\text { peoples' care makes me feel afraid }\end{array}$ & $5.58(1.62)$ & $3.73(1.85)$ & 78.45 & 0.00 \\
\hline $\begin{array}{l}\text { 18. If I was exposed to a terrorist attack, I would not share it with anyone except my } \\
\text { family }\end{array}$ & $2.51(1.72)$ & $1.85(1.24)$ & 16.00 & 0.00 \\
\hline 24. If I was exposed to a terrorist attack, I would be killed & $3.35(1.51)$ & $3.66(1.28)$ & 3.59 & 0.06 \\
\hline 27. I cannot live as a person who has been exposed to a terrorist attack & $2.03(1.54)$ & $1.98(1.23)$ & 0.01 & 0.95 \\
\hline
\end{tabular}


There were no significant differences between the two samples in mean ratings of costs, vulnerability, and trust. Both groups had high perceptions of costs and vulnerability, and moderate trust in authorities, but there was a significant difference between the two samples in mean ratings of control: Turkish participants felt less control than Israelis over the risk that they will be victims of a terror attack. Because of the significant differences in age, gender, and perceived knowledge between the two samples, the analyses were repeated using MANCOVA to control for the effects of these variables. The analysis yielded again a significant difference in mean ratings of control $(p<$ 0.001 ), leading us to conclude that the differences between the groups did not result from diversities in backgrounds.

Among the nine eliminated items, MANCOVA revealed significant cross-country differences in five items: "Thinking that those who are close to me can be exposed to terrorist attacks makes me feel afraid," "Thinking that I can be exposed to a terrorist attack makes me feel anxious," "Working in companies that can be targets of the terrorist groups will increase my chance of being exposed to a terrorist attack," "If I was exposed to a terrorist attack, the possibility that I might need other peoples' care makes me feel afraid," and "If I was exposed to a terrorist attack, I would not share it with anyone except my family." Mean scores of all these items were higher in the Turkish sample.

Analyses of the affective scores yielded significant intergroup differences in all emotions and overall negative affect, except for helplessness. When the data were subjected to MANCOVA to control for the effects of age, gender, and perceived knowledge, the significant differences remained. Controlling the effect of the "control" cognitive factor did not change the results either. Thus, Turkish participants were more emotional over terrorist attacks than their Israeli counterparts. Sadness was the strongest emotion among Israeli participants, and anger was the strongest emotion among Turkish participants. Loneliness was the least reported emotion among both Turkish and Israeli participants.

\section{DISCUSSION}

Four independent factors of cognitive themes represented terror risk perceptions in both samples: costs (consequences of being victimized by a terror attack), vulnerability (relative chance of being a victim of a terror attack), trust in authorities, and perceived (lack of) control. The first two factors (i.e., costs and vulnerability) represent the two technical determinants of risk analysis-magnitude of losses and probability of their occurrence. The last two factors (i.e., trust in authorities and control) represent the fact that in the context of safety, the concept of risk involves judgments that reflect much more than the probability and consequences of the occurrence of an event. In line with the well-established literature (e.g., Slovic, 1999, 2001), our findings show that terror risk perceptions are inherently subjective and represent a blending of science and judgment with psychological, social, and cultural factors. Our study thus supports the claim that perceived risk of terror has properties similar to those of other risk perceptions (Sjoberg, 2004).

Trust in authorities was previously recognized as playing a central role in risk perception of hazardous technologies (Siegrist, Gutscher, \& Earle, 2005; Slovic, 1993). It was considered especially important when issues are too big and complex for individuals to manage themselves (Poortinga \& Pidgeon, 2005). Strong correlations were found between social trust and estimated risk for hazards about which people did not have much knowledge, but not for hazards about which people were knowledgeable (Siegrist \& Cvetkovich, 2000). In our samples, trust in authorities was not correlated with other subscales of perceived terror risk; this may reflect the respondents' moderate/high levels of self-assessed knowledge about terror attacks, potentially stemming from the extensive publicity surrounding the pertinent events. However, the fact that trust in authorities emerged as a key element in the representation of terror risk suggests that it is perceived as a threat too immense and complex for personal management, which may be associated with other subscales of terror risk perceptions in other societies that are less knowledgeable about those risks.

Helplessness and perceived control were aggregated to constitute another factor (labeled as control) in the representation of terror risk in our study. This concurs with viewing perceived lack of control as a significant component of the multidimensional concept of subjective risk (Fischhoff et al., 1978). We found in both samples that lower perceived control and higher perceived costs correlated with stronger negative emotions about terror. Similarly, it was found that perceived control explained the variance in perceived risk for future electrocution events among employees of a recreational facility where a lifeguard was accidentally electrocuted (Greening, 1997). In addition, internal locus of control and breast-cancer-specific 
perceived control was found to predict perceived risk, as measured by the certainty of remaining free of breast cancer (Rowe et al., 2005). Studies about perceived food risks, on the other hand, found no direct relationship between perceived control and perceived risk and concerns (Frewer, Shepherd, \& Sparks, 1994; Knight \& Warland, 2005). It may therefore be argued that perceived lack of control over a risk is associated with more concern and negative affect only with regard to risks of sudden, catastrophic events (like terror, electrocution, diagnosis of cancer), and not for milder ongoing and accumulating risks. This provides a promising venue for further comparative studies.

Our findings also support the view that representations of risk consist of both affective and cognitive variables (Holtgrave \& Weber, 1993). Participants in our study expressed a variety of negative emotions, ranging in intensity from anger and sadness to loneliness. In both samples, mean negative emotions were associated with perceiving more costs and less control, and in the Turkish sample also with perceiving higher vulnerability. This is in line with extensive evidence of links between risk perception and affect (e.g., Alhakami \& Slovic, 1994; Slovic et al., 2004; Finucane et al., 2000; Lerner \& Keltner, 2001). In particular, Loewenstein et al. (2001) pointed out that emotional reactions to risky situations often diverge from cognitive assessments of these risks, and Slovic et al. (2004) reasoned that most risk analysis is handled quickly and automatically by affect through an experiential mode of thinking. Our findings also signal a strong need to include affect in studying perceptions of risk.

Associations were also found between gender and representations of terror risk. Females perceived more costs and vulnerability, and reported more negative affect in both samples. Israeli women also felt less control than men. These results are consistent with gender differences in representations of and reactions to terror risks reported from different countries, thus lending support to the validity of the control factor of the TRPQ, despite its low reliability. Higher perceived threat of terrorist attacks was associated with female gender in Britain (Goodwin, Willson, \& Gaines, 2005), and in the United States, gender differences in emotions were associated with gender differences in perceived terror risk (Lerner et al., 2003). Furthermore, females were more prone to marked short-term posttraumatic stress among a large nonWestern sample after the attack on the U.S. embassy in Nairobi (Nyenga et al., 2004), and among American women after 9/11 (Pulcino et al., 2003). Women's behavior was also affected more than men's in a retrospective study about reactions to the sniper who terrorized the Washington, DC metropolitan area for 3 weeks in October 2002 (Zivotofsky \& Koslowsky, 2005).

Self-assessed knowledge of terror attacks was found to be associated with higher perceived vulnerability among Israelis and with more trust in authorities in the Turkish sample. Subjective perceived knowledge about terrorist attacks may reflect excessive information about the attacks. Higher vulnerability perceptions in the Israeli sample may therefore relate to the "availability heuristic" (Tversky \& Kahneman, 1974), the tendency to judge events to be more likely or frequent when instances thereof come more easily to mind. As a result, Israelis to whom information about terror attacks was more accessible may have estimated their personal chances of being stricken by them as higher. Israelis with more personal experience with terror also expressed more negative feelings. These results are consistent with findings that perceptions and responses to risk are more strongly related to exposure to the risk than to its magnitude (Renn et al., 1992). Interestingly, a different process may explain why subjective knowledge was related to trust in authorities in the Turkish sample. The trust factor was suggested to be a mechanism for coping with risks perceived as being beyond personal control, as in food risks (Knight \& Warland, 2005). It is possible that those with higher subjective knowledge in the Turkish group coped with the threat by increasingly trusting that authorities can be relied upon for protection. It is worth noting that such potential explanations are based on theoretical considerations and require further empirical validation.

Our findings also support the views presented by the social amplification of risk framework (Kasperson et al., 1988) about social processes that affect representations of risks by individuals and groups across different cultural/societal contexts. It replicated previous findings that risks have a common universal dimensional structure, but that cultures differed with regard to the salience of associated factors (Slovic, 1992), and supported our prediction of a common structure of terror risk perception together with cultural differences in the perceived salience of specific factors. The two samples showed similar structures of cognitive and emotional components of terror risk perceptions, and also did not differ in perceptions of costs, vulnerability, and trust in authorities. However, Turkish participants perceived less control, 
and expressed more negative affect, than the Israeli sample. The single eliminated items also revealed more negative perceptions in the Turkish sample. The higher control perceptions among Israeli compared to Turkish participants concurs with data showing increased mastery values in Israel compared to Turkey (Schwartz, 1999). These findings lend more support to the validity of the control factor of the TRPQ, despite its low reliability. The intergroup differences cannot be explained by differences in demographic variables (gender, age) or reported knowledge, which were statistically controlled. They may, however, be related to background factors that were not included in this study, like military service, or to other cultural differences.

The causes of cultural differences in terror risk perceptions, such as that found in our study, can also be explained by the cultural theory of risk perception (Kahan \& Braman, 2003; Kahan et al., 2005), maintaining that people form distinct attitudes toward risk in a manner that protects from interference with the activities on which their status depends (Kahan \& Braman, 2003; Kahan et al., 2005; Peters \& Slovic, 1996). Schwartz, Sagiv, and Boehnke (2000) also postulated that culture-related value priorities influence worries by increasing attention to and perception of threats to valued goals. Accordingly, future research investigating the potential effects of cultural worldviews and status anxiety on cross-cultural differences in perceived risk of terror may enhance our conceptualization of risk perception.

Studies on other cultural groups showed associations between culture and factors that may be related to terror risk representations. For example, Australian and Japanese cultures differed in type of mortality that produces the greatest levels of anxiety and the manner in which a given worldview is used to cope with anxiety about mortality (Kashima et al., 2004). Hispanics were more likely than others to report symptoms of PTSD after 9/11 in New York, differences that could also be explained by socioeconomics, event exposure, social support, and peri-event emotional reactions (Galea et al., 2004). In a study among different ethnic groups, Europeans attained the overall highest internal locus of control scores and Caribbean participants had the highest scores on external locus of control (Dunckley \& Smith, 2000). Whether factors like mortality representations or locus of control explain the currently reported differences between Turkish and Israeli terror risk representations remains to be determined.

\subsection{Limitations of the Study}

The qualitative study upon which items for our questionnaire were generated came from just one (Turkey) of the two countries studied. This means that the scope of themes generated might not be representative of the universe of potential items. It is, therefore, recommended to continue collecting more qualitative data from multiple countries and see whether more relevant themes that have been missed here should be included as items in the questionnaire.

The unsatisfactory reliability of the control subscale is another limitation in this study. It can be attributed to the small number of items (3) included in this scale, suggesting that adding more items may improve its reliability. It is interesting to note that despite its relatively low reliability, the control subscale yielded some of the more interesting and valid results with regard to group comparisons. Improving its reliability might, therefore, strengthen its explanatory significance even more.

Participants in this study were two relatively small samples of young university students. It is possible that their representations of terrorist risk do not represent those of people from different demographic and socioeconomic backgrounds in their countries. It is, therefore, important to be cautious in drawing overly broad conclusions from our findings. Further research using the current instrument in other groups of people is highly desirable.

Our research asked participants about terror attacks in general. Further validation of our findings can be achieved by using complementary study designs. For example, asking participants to recall as many instances as possible of terrorist attacks in recent years, and undertaking a comprehensive multidimensional scaling analysis and/or cluster analysis of their judgments of these events. This would enable to compare directly how particular terrorist incidents were organized within these representations. Cross-country comparisons could then be undertaken not only in respect of these representations but also regarding the extent to which there are systematic differences in terms of the incidents recalled and the attributes associated with them.

\subsection{Conclusions and Implications}

The current study involved (1) developing a questionnaire that measures the cognitive and affective components of terror risk perception, and (2) applying this questionnaire in two countries with terror 
experience: Turkey and Israel. The replications of structure, reliabilities, intercorrelations, and gender differences in both samples provide support for the value of this questionnaire as potentially a "standard" measure for future research. The existence of a standard measure is a prerequisite for cross-cultural comparisons and insights about this global risk. The Terror Risk Perception Questionnaire developed in this study provides an essential starting point in this direction. We see the questionnaire in its current form as a first-stage of a measure that should be further developed and improved by researchers in different parts of the world.

Slovic (2001) conceptualized risk as a game in which the rules must be socially negotiated within the context of a specific problem. He suggested taking the social amplification of risk into account in "vulnerability analysis," which characterizes the forms of physical, social, political, economic, cultural, and psychological harms to which individuals and modern societies are susceptible (Slovic, 2002). Such a contextualized view of risk was applied in the present study, which focused on perceptions of terror risk in specific cultures. This study also applied principles derived from self-regulatory theories (e.g., Lazarus \& Folkman, 1984; Leventhal, 1970) by highlighting the role of personal representations that, according to these theories, regulate individuals' responses to threats.

This approach has practical implications. In preparing public health workers to deal with terror events, risk perceptions may influence their willingness to report to duty during disasters (Shapira et al., 1991), as well as their ability to provide effective emergency risk communication to an anxious public (Barnett et al., 2005). Cognitive and emotional representations can also predict policy endorsement. After the $9 / 11$ attacks, people whose emotional reactions were dominated by anger attributed the attacks to fanaticism of the terrorists and to poor U.S. security and endorsed an aggressive military response; those whose emotional reactions were dominated by sadness or fear expressed reservations about a strong military reaction (Sadler et al., 2005).

Fischhoff et al. (2003) pointed out that understanding the psychology of the public is important for anticipating how people will respond to any plans formulated to deal with terror attacks. It is clearly important that professionals and policymakers understand how citizens perceive and react to terror attacks in order to determine how to communicate terror risks. Cognitive and affective representations of terror risk identified in our study may predict who will be most affected by terror, and suggest interventions to promote resilience at an individual and population level. For example, we found that trust in authorities plays a role in terror risk perception. Therefore, a better understanding of the "dynamics of the system" that affect trust (Slovic, 1993) may have important implications for how we approach terror risk perception and management, and how we cope with these threats in the future.

\section{ACKNOWLEDGMENTS}

This study was done in partial fulfillment of the doctoral dissertation of the second author. This research was supported in part by a grant from the Academic Research Program of the Israeli Foreign Ministry, the Moshe Dayan Center's Suleyman Demirel Program for Contemporary Turkish Studies, and by an appointment of the first author to the Senior Fellowship Program at the National Institutes of Health. This program is administered by the Oak Ridge Institute for Science and Education through an interagency agreement between the U.S. Department of Energy and the National Institutes of Health.

\section{REFERENCES}

Adams, M. L., Ford, J. D., \& Dailey, W. F. (2004). Predictors of help-seeking among Connecticut adults after September 11, 2001. American Journal of Public Health, 94, 1596-1602.

Adams, R. E., Boscarino, J. A., \& Galea, S. (2006). Social and psychological resources and health outcomes after the World Trade Center disaster. Social Science \& Medicine, 62, 176-188.

Aiken, L. R. (1994). Psychological Testing and Assessment, 8th ed. Boston: Allyn and Bacon.

Alhakami, A. S., \& Slovic, P. (1994). A psychological study of the inverse relation between perceived risk and perceived benefit. Risk Analysis, 14, 1085-1096.

Allen, M. W., Ng, S. H., \& Leiser, D. (2005). Adult economic model and values survey: Cross-national differences in economic beliefs. Journal of Economic Psychology, 26, 159-185.

Baca Baldomero, E., Cabanas Arrate, M. L., Perez Rodriguez, M. M., \& Baca Garcia, E. (2004). Mental disorders in victims of terrorism and their families. Medicina Clinica, 122, 681685.

Barnett, D. J., Balicer, R. D., Blodgett, D. W., Everly, G. S., Omer, S. B., Parker, C. L., et al. (2005). Applying risk perception theory to public health workforce preparedness training. Journal of Public Health Management and Practice, Suppl. Nov., S33-S37.

Bergstrom, R. L., \& McCaul, K. D. (2004). Perceived risk and worry: The effects of 9/11 on willingness to fly. Journal of Applied Social Psychology, 34, 1846-1856.

Bleich, A., Gelkopf, M., \& Solomon, Z. (2003). Exposure to terrorism, stress-related mental health symptoms, and coping behaviors among a nationally representative sample in Israel. Journal of the American Medical Association, 290, 612-620.

Cattell, R. B. (1978). The Scientific Use of Factor Analysis in Behavioral and Life Sciences. New York: Plenum. 
Deisler, P. F. (2002). A perspective: Risk analysis as a tool for reducing the risk of terrorism. Risk Analysis, 22, 405-413.

Dunckley, L., \& Smith, A. (2000). Cultural factors and user inzterface design. In Proceedings of the IEA 2000/HFES 2000 Conference (pp. 537-540). San Diego, CA.

Fife, B. L. (2005). The role of constructed meaning in adaptation to the onset of life-threatening illness. Social Science \& Medicine, 61, 2132-2143.

Finucane, M. L., Alhakami, A., Slovic, P., \& Johnson, S. M. (2000). The affect heuristic in judgments of risks and benefits. Journal of Behavioral Decision Making, 13, 1-17.

Finucane, M. L., \& Holup, J. L. (2005). Psychological and cultural factors affecting the perceived risk of genetically modified food: An overview of the literature. Social Science and Medicine, 60, 1603-1612.

Fischhoff, B., de Bruin, W. B., Perrin, W., \& Downs, J. (2004). Travel risks in a time of terror: Judgments and choices. Risk Analysis, 24, 1301-1309.

Fischhoff, B., Gonzalez, R. A., Lerner, J. S., Small, D. A. (2005). Evolving judgments of terror risks: Foresight, hindsight, and emotion. Journal of Experimental Psychology-Applied, 11, 124-139.

Fischhoff, B., Gonzalez, R. M., Small, D. A., \& Lerner, J. S. (2003). Judged terror risk and proximity to the World Trade Center. Journal of Risk and Uncertainty, 26(2/3), 137-151.

Fischhoff, B., Slovic, P., Lichtenstein, S., Read, S., \& Combs, B. (1978). How safe is safe enough? A psychometric study of attitudes toward technological risks and benefits. Policy Sciences, 9, 127-152.

Frewer, L. J., Shepherd, R., \& Sparks, P. (1994). The interrelationship between perceived knowledge, control and risk associated with a range of food-related hazards targeted at the individual, other people and society. Journal of Food Safety, 14, 19-40.

Galea, S., Vlahov, D., Tracy, M., Hoover, D. R., Resnick, H., \& Kilpatrick, D. (2004). Hispanic ethnicity and post-traumatic stress disorder after a disaster: Evidence from a general population survey after September 11, 2001. Annals of Epidemiology, 14, $520-531$.

Gigerenzer, G. (2004). Dread risk, September 11, and fatal traffic accidents. Psychological Science, 15, 286-287.

Goodwin, R., Willson, M., \& Gaines, S. (2005). Terror threat perception and its consequences in contemporary Britain. British Journal of Psychology, 96, 389-406.

Greening, L. (1997). Risk perception following exposure to a jobrelated electrocution accident: The mediating role of perceived control. Acta Psychologica, 95, 267-277.

Heine, S. J., \& Lehman, D. R. (1995). Cultural variation in unrealistic optimism: Does the west feel more invulnerable than the east. Journal of Personality and Social Psychology, 68, 595-607.

Holtgrave, D., \& Weber, E. U. (1993). Dimensions of risk perception for financial and health risks. Risk Analysis, 13, 553-558.

Jordan, N. N., Hoge, C. W., Tobler, S. K., Wells, J., Dydek, G. J., \& Egerton, W. E. (2004). Mental health impact of 9/11 Pentagon attack validation of a rapid assessment. American Journal of Preventive Medicine, 26, 284-293.

Kahan, D. M., \& Braman, D. (2003). More statistics, less persuasion: A cultural theory of gun-risk perceptions. University of Pennsylvania Law Review, 151, 1291-1327.

Kahan, D. M., Braman, D., Gastil, J.. Slovic, P., \& Mertz, C. K. (2005). Gender, Race, and Risk Perception: the Influence of Cultural Status Anxiety. Yale Law School, Public Law Working Paper No. 86.

Kashima, E. S., Halloran, M., Yuki, M., \& Kashima, Y. (2004). The effects of personal and collective mortality salience on individualism: Comparing Australians and Japanese with higher and lower self-esteem. Journal of Experimental Social Psychology, 40, 384-392.
Kasperson, R. E., Renn, O., Slovic, P., Brown, H. S., Emel, J., Goble, R., et al. (1988). The social amplification of risk: A conceptual framework. Risk Analysis, 8, 177-187.

Kinman, G., \& Jones, F. (2005). Lay representations of workplace stress: What do people really mean when they say they are stressed? Work and Stress, 19,101-120.

Knight, A. J., \& Warland, R. (2005). Determinants of food safety risks: A multi-disciplinary approach. Rural Sociology, 70, 253275.

Lam, L. T. (2005). Parental risk perceptions of childhood pedestrian road safety: A cross cultural comparison. Journal of Safety Research, 36, 181-187.

Lange, L. J., Fleming, R., \& Toussaint, L. L. (2004). Risk perceptions and stress during the threat of explosion from railroad accident. Social Behavior and Personality, 32, 117-127.

Lavi, T., \& Solomon, Z. (2005). Palestinian youth of the Intifada: PTSD and future orientation. Journal of the American Academy of Child and Adolescence Psychiatry, 44, 1176-1183.

Lazarus, R. S., \& Folkman, S. (1984). Stress, Appraisal and Coping. New York: Springer.

Lerner, J. S., Gonzalez, R. M., Small, D. A., \& Fischhoff, B. (2003). Effects of fear and anger on perceived risks of terrorism: A national field experiment. Psychological Science, 14, 144-150.

Lerner, J. S., \& Keltner, D. (2001). Fear, anger and risk. Journal of Personality and Social Psychology, 81, 146-159.

Leventhal, H. (1970). Findings and theory in the study of fear communications. Advances in Experimental Social Psychology, 5, 119-186.

Loewenstein, G. F., Weber, E. U., Hsee, C. K., \& Welch, E. (2001). Risk as feelings. Psychological Bulletin, 127, 267-286.

McDaniels, T. L., \& Gregory, R. S. (1991). A framework for structuring cross-cultural research in risk and decision making. Journal of Cross-Cultural Psychology, 22, 103-128.

McIntire, S., \& Miller, L. (2000). Foundations of Psychological Testing. Boston: McGraw-Hill.

North, C. S., Pfefferbaum, B., Narayanan, P., Thielman, S., McCoy, G., Dumont, C., Kawasaki, A., et al. (2005). Comparison of post-disaster psychiatric disorders after terrorist bombings in Nairobi and Oklahoma City. British Journal of Psychiatry, 186, 487-493.

Nyenga, F. G., Nicholls, P. J., Nyamai, C., Kigamwa, P., \& Davidson, J. R. T. (2004). Post-traumatic stress after terrorist attack: Psychological reactions following the US embassy bombing in Nairobi-Naturalistic study. British Journal of Psychiatry, 185, 328-333.

Peters, E., \& Slovic, P. (1996). The role of affect and world-views as orienting dispositions in the perception and acceptance of nuclear power. Journal of Applied Social Psychology, 26, 14271453.

Poortinga, W., \& Pidgeon, N. F. (2005). Trust in risk regulation: Cause or consequence of the acceptability of GM food? Risk Analysis, 25, 199-209.

Pulcino, T., Galea, S., Ahern, J., Resnick, H., Foley, M., \& Vlahov, D. (2003). Posttraumatic stress in women after the September 11 terrorist attacks in New York City. Journal of Womens' Health, $12,809-820$.

Renn, O., Burns, W., Kasperson, J., Kasperson, R., \& Slovic, P. (1992). The social amplification of risk-Theoretical foundations and empirical applications. Journal of Social Issues, 48, $137-160$.

Rowe, J. L., Montgomery, G. H., Duberstein, P. R., \& Bovbjerg, D. H. (2005). Health locus of control and perceived risk for breast cancer in healthy women. Behavioral Medicine, 31, 33-40.

Sadler, M. S., Lineberger, M., Correll, J., \& Park, B. (2005). Emotions, attributions, and policy endorsement in response to the September 11th terrorist attacks. Basic and Applied Social Psychology, 27, 249-258. 
Sakamoto, S., Kijima, N., Tomoda, A., \& Kambara, M. (1998). Factor structures of the Zung self-rating depression scale (SDS) for undergraduates. Journal of Clinical Psychology, 54, 477487.

Schwartz, S. H. (1999). A theory of cultural values and some implications for work. Applied Psychology: An International Review, 48, $23-47$.

Schwartz, S. H., Sagiv, L., \& Boehnke, K. (2000). Worries and values. Journal of Personality, 68, 309-346.

Shapira, Y., Marganitt, B., Roziner, I., Shochet, T., Bar, Y., \& Shemer, J. (1991). Willingness of staff to report to their hospital duties following an unconventional missile attack: A state-wide survey. Israel Journal of Medical Sciences, 27, 704-711.

Siegrist, M., \& Cvetchvich, G. (2000). Perception of hazards: The role of social trust and knowledge. Risk Analysis, 20, 713-719.

Siegrist, M., Gutscher, H., \& Earle, T. C. (2005). Perception of risk: The influence of general trust, and general confidence. Journal of Risk Research, 8, 145-156.

Sjoberg, L. (2004). Editorial: Asking questions about risk and worry: Dilemmas of the pollsters. Journal of Risk Research, 7, 671-674.

Slovic, P. (1987). Perception of risk. Science, 236, 280-285.

Slovic, P. (1992). Perception of risk: Reflections on the psychometric paradigm. In S. Krimsky \& D. Golding (Eds.), Social Theories of Risk (pp. 117-152). New York: Praeger.

Slovic, P. (1993). Perceived risk, trust, and democracy. Risk Analysis, $13,675-682$.

Slovic, P. (1999). Trust, emotion, sex, politics, and science: Surveying the risk-assessment battlefield. Risk Analysis, 19, 689701
Slovic, P. (2001). The risk game. Journal of Hazardous Materials, 86(Suppl.), 17-24.

Slovic, P. (2002). Terrorism as hazard: A new species of trouble. Risk Analysis, 22, 425-426.

Slovic, P., Finucane, M. L., Peters, E., \& MacGregor, D. G. (2004). Risk as analysis and risk as feelings: Some thoughts about affect, reason, risk, and rationality. Risk Analysis, 24, 311-322.

Sunstein, C. R. (2003). Terrorism and probability neglect. Journal of Risk and Uncertainty, 26, 12-136.

Tabachnik, B. G., \& Fidell, L. S. (1996). Using Multivariate Statistics, 3rd ed. New York: Harper Collins College Publishers.

Tversky, A., \& Kahneman, D. (1974). Judgment under uncertainty-Heuristics and biases. Science, 185, 1124-1131.

Verger, P., Dab, W., Lamping, D. L., Loze, J. Y., DeschaseauxVoinet, C., Abenhaim, L., et al. (2004). The psychological impact of terrorism: An epidemiologic study of posttraumatic stress disorder and associated factors in victims of the 19951996 bombings in France. American Journal of Psychiatry, 161, 1384-1389.

Weber, E. U., \& Hsee, C. (1998). Cross cultural differences in risk perception but cross-cultural similarities in attitudes towards perceived risk. Management Science, 44, 1205-1217.

Woike, B., \& Matic, D. (2004). Cognitive complexity in response to traumatic experiences. Journal of Personality, 72, 633-657.

Zeidner, M. (2005). Contextual and personal predictors of adaptive outcomes under terror attack: The case of Israeli adolescents. Journal of Youth and Adolescence, 34, 459-470.

Zivotofsky, A. Z., \& Koslowsky, M. (2005). Short communication: Gender differences in coping with the major external stress of the Washington, DC sniper. Stress and Health, 21, 27-31. 